\title{
监理工程师如何做好现场的监理工作
}

\author{
吴晓宇 \\ 浙江东方工程管理有限公司
}

DOI:10.32629/btr.v1i4.1592

[摘 要] 随着我国建筑工程项目设计结构的复杂化与投资规模的扩大化,监理工作的业务量与难度逐渐加大。在建筑施工的 过程中,监理起到着相当重要的作用。可以说监理执行的好坏将在很大程度上影响建筑工程施工的质量和进度。工程施工质 量的好坏直接影响着人身关系的安全,一些重要工程质量甚至还会对周边的信息建设有一定的影响。本文以监理工程师的监 理工作为研究对象, 探讨了监理工程师如何才能做好现场的监理工作, 旨在提高建筑工程监理的质量和效率。

[关键词] 监理工程师; 监理; 建筑工程

建设工程监理是目前我国建筑工程管理的主流模式, 在 推动我国经济建设的发展中发挥了巨大作用。建筑施工是一 项十分庞大而复杂的工程, 技术含量高、劳动强度大。想要 确保施工质量, 必须做好建筑工程的监理工作, 监理是建筑 工程质量监督必不可少的组成部分, 是保障建筑工程质量的 重要环节。监理工程师作为建筑工程监理工作的直接把控者 和执行者, 责任重大。如何做好监理工作, 是每一位监理工程 师必须思考的问题, 也是整个建筑行业发展所要面对的问 题。

\section{1 监理工程师职责分析}

1.1 以质量控制为中心

监理工程师在工作中会对建筑工程的项目投资、工程进 度、生产安全等方面进行控制, 最终的目的是保证工程的质 量, 使工程质量达到设计要求和使用要求。如果工程失去了 质量保证, 质量低劣, 存在安全隐患, 监理所做的其他管控工 作也就毫无意义。所以, 监理工程师要牢固树立 “百年大计, 质量第一” 的思想, 以质量控制为中心, 引导和开展自己的各 项工作。

1.2 增强责任意识和廉洁意识

(1) 责任意识。这对于一个监理工程师来说至关重要。 责任意识关系到监理工作是否到位, 进而影响工程的质量控 制。如果没有足够的责任心, 不管监理工程师的专业素质有 多高, 其监理工作没有源动力, 会浮于表面, 监理工作难以做 到实处。

(2) 廉洁意识。监理工程师在监理执行中, 要对不合格的 工程叫停, 并督促施工方返工; 对不合格的建筑材料和施工 设备做出拒绝进场和使用的决定; 对不符合施工安全的情况 要求施工方进行整改。以上情况都会引起施工方或建设方建 设成本的增加, 监理人员也会因此受到侵蚀。如果监理人员 不能廉洁自律, 工程的质量控制就会大打折扣, 造成质量失 控。所以, 要加强廉洁意识, 对不符合要求的工程不留情面。

\section{3 把握审查审批和巡视旁站环节}

(1) 把握审查审批环节。施工组织、施工方案、施工工 艺是否合理、, 原材料质量是否符合要求, 质量控制参数是否
准确, 开工条件是否具备等等, 都是需要监理工程师进行审 查和审批的环节。监理工程师要按照详细的审查审批信息, 严格按照相关流程, 履行监理的职责, 对不按监理程序履行 相关手续的施工方和人员进行制止, 并予以纠正, 使审查和 审批工作落到实处。

(2) 把握巡视旁站环节。监理旁站和巡视是监理工作的 重要方式, 也是实现工程质量控制的重要手段, 监理工程师 一定要贯彻执行。施工工艺、施工操作是否符合施工要求, 工程结构是否与设计方案一致, 施工防护措施是否满足安全 生产的要求等都可以通过监理旁站进行解决。监理旁站将质 量隐患消灭在萌芽状态, 同时对质量缺陷制定具有针对性的 措施进行纠正, 是施工现场发现问题、解决问题的关键环节。 此外, 监理人员每天要对工程进行一次全面的巡检, 将巡检 结果和巡检中发现的问题, 形成文字记录, 存档。

\section{2 监理工程师如何做好建筑工程的监理工作}

2.1 要尽可能的完善自身的整体素质来满足监理工作的 需要

随着时代与经济的快速发展, 项目业主对监理工程师也 提出了更高的要求。作为一名项目监理工程师, 要想更好的 适应这份工作, 就需要不断的提升自我的各项能力来战胜监 理工程师的工作。首先监理工程师要在思想上有所觉悟。众 所周知, 监理工程师的工作环境并不同于一般白领的优越工 作条件, 他们需要深入到艰苦的项目工作中, 其中涉及到的 很多工作都是在野外的艰苦环境中完成的。所以监理工程师 必须要对自己的工作有着高度的热情和奉献的精神。自愿为 国家建设作出自己的一份微薄的力量。当然监理工程师作为 各方与各个事项的协调者, 需要在问题产生时能够以公平公 正的心态来处理各项事物, 协调各种关系, 不能为了满足自 己的私欲而偏护某一方。其次, 由于监理工程师处于一种较 为艰苦的工作环境, 他们不仅要煎受烈日炎炎的考验, 也要 饱受冰霜雪露的苦打, 因而监理工程师有必要锻炼一个健壮 的体魄来适应艰苦的工作。再次监理工程师要不断的完善自 身的业务素质, 监理工程师要具有扎实的理论知识。理论知 识是监理工程师为了顺利开展下一阶段的工作所要具备的 
前提条件。其中包括了一定的管理、经济、心理和法律知识, 也就是说监理工程师只有在此理论知识的支撑下才能更好 的解决监理中出现的合同, 协调等问题。同时监理工程师还 要具有丰富的实际操作能力, 对于事前预测、事中控制和事 后监督, 监理人员都要对工程的进度、造价和质量有一个全 面统筹和管理的意识, 在丰富经验的积累中尽可能的减少各 种监理事故的产生。

\section{2 准备阶段对工程质量的控制}

在工程项目开工前, 项目监理部就应当对施工技术方案 等内容进行严格审查, 确保能保证工程项目施工质量、方案 合理可行、质量能达到预期效果后再予以签认, 防患于未然。

(1) 依据工程合同, 确定工程项目质量总目标。依据工程 合同, 确定好工程项目质量目标后, 将项目的总目标分解成 多个质量分目标, 并将各个分目标落实到各个部门、团队、 分包方和供货方, 直至施工作业班组及负责人, 如果情况需 要, 可签订责任协议或合同。

(2) 严格审阅设计图纸。在建筑工程开工之前, 监理人员 一定要严格审阅设计图纸。由项目技术负责人组织有关工程 技术人员与管理人员对施工图纸及设计说明进行仔细研究, 理解设计的目的, 从而更好地掌握设计的要求。审阅过程中 如发现问题, 先进行内部图纸会审, 然后将问题进行集中归 纳参加设计交底及设计图纸会审, 并向设计者提出问题, 便 于采纳或修改。在施工过程中, 如果发现问题或出现材料、 设备等改变时, 都必须与业主沟通, 通过业主向设计师提出 修改意见并获得设计修改, 监理人员不得随意修改。同时, 对于施工单位的技术水平与组织设计, 监理人员也要把关, 找出施工中可能出现的质量问题, 与建筑工程单位进行沟通, 找出合理的解决办法, 避免建筑质量问题的发生。

(3) 确保工程所需建筑材料的质量。合格的建筑材料质 量是保证工程质量前提条件。在建筑材料的选购上, 首先, 要求施工单位必须注重质量管理, 采购符合标准的建筑材 料。其次, 监理人员应加强对建筑材料质量的监督, 因为, 钢 筋、水泥等材料使用量大、进货渠道混乱, 所以, 在对工程所 需的钢筋、水泥进场资料进行检查时, 严格把关, 资料不齐的 不允许进场, 只有通过检验的建筑材料才允许进入场地使 用。同时对于半成品的材料, 如钢筋焊接半成品, 如检查不符
合要求也不得使用。严格把好建筑材料质量关, 确保建筑工 程质量。

2.3 要具有前瞻性的统筹眼光

我们做一切事情都要抱着“防患于未然” 的眼光和态度, 工程监理工作也是如此, 监理师作为多方的协调者要具有统 筹的管理眼光, 才能更好的做到 “事前预测”。第一严格做到 审查和履行各方签订的合同。在经济迅速发展的当今社会, 各种各样的建筑物拔地而起, 任务量巨大的工作压力难免会 给施工带来诸多不利的影响, 这就需要业主和承包方要在施 工前尽可能的完善工程施工的合同, 以避免在施工过程中出 现责任不明的状况。而监理方就需要对业主和承包方签订的 合同进行严格的审查和监督。监理工程师要先对合同进行一 番细致的审查, 确保合同中不存在责任不明的盲点和漏洞, 杜绝业主和承包方的任何一方利用合同中的盲点和漏洞来 谋取自己的私欲。之后监理工程师就要监督双方认真履行所 签订的合同, 严格按照合同的要求进行人员和物资的分配, 让合同成为施工顺利进展的有力保障。第二做好工作前的准 备工作。工程施工中所涉及到的工作都是环环相扣的, 其中 任何一个环节出现问题, 都会直接影响到整个工程的施工质 量和施工进展, 因而监理工程师在施工前要做到整体的统筹 工作。监理工程师要力图制定和完善工程施工的所有环节, 对施工中出现的任何问题都要有充足的预测和把握。要清楚 施工的每一步应该做什么, 应该怎么做, 一旦出现了问题应 该怎样去解决等等。

\section{3 结束语}

总之。监理工程师必须要不断的提升自我的综合素质, 并培养自己长远的统筹眼光。在此基础之上加强对项目业 主、承包方和监理内部的沟通协调。

\section{[参考文献]}

[1]高学杰, 如何做好总监理工程师工作的思考与体会 [J] 建设监理,2013,(03):48.

[2]林东,谈如何做好现场监理工作[J]广东建材.2013,(03):57.

[3]单晓杰. 监理工程师如何做好建筑工程的监理工作 [J].中小企业管理与科技(下旬刊),2012,(02):78.

[4]鲍希平.关于如何做好建筑工程监理工作探索 [J].科 技致富向导,2013,(12):56. 